\title{
A Study of the Database Construction in University Libraries with the Characteristics of Key Subjects Orientation
}

\author{
Maoli Xu \\ library, \\ JiLin Agricultural University , \\ Changchun, China \\ Email:xmljlau@yeah.net
}

Key words: key subjects, university libraries, database with characteristics, database construction

\begin{abstract}
This thesis briefly introduces database construction with the characteristics of the Chinese university libraries as well as its significance and principles. The corresponding countermeasures are proposed from the reality.
\end{abstract}

\section{Introduction}

Universities, as an important research base, have the distinct advantages in key subjects and the remarkable subject characteristics. In order to meet the needs of development and progress of various subjects in the information society which is characterizedbythe utilization and dissemination of knowledge, the libraries, as the supportive bases of literature resources for universities, gradually transform their service from the construction of resource to the service for subjects.Moreover, they endeavor to explore the establish knowledge environment of disciplinary database, especially for the service-oriented resources system of the key subjects. To take this opportunity, the university libraries should rely on the unique subject advantages of their own, with the fundamental starting point of "disciplinary service". They should combine the resources with the advantages of Library and Information Science, with the commitment to the database construction with the characteristics of key subjects.

A digital resource system with the distinct characteristics of subjects should be built by the comprehensive collection of all types of information in a certain field, the integration of information resources, resource navigation and the further exploration of knowledge.

\section{Significance of the database construction with characteristics}

The database construction with characteristics is defined as: to meet the needs for information of users,the information resource base of personalized demands can be built after collecting, analyzing, evaluating, processing and storing the information resources ofa particular subject or theme $^{[1]}$. It is the major information resourcefor the digital libraries' information services, and it is another manifestation of traditional library collection in the digital age. The significance of database construction in university library mainly lies in the following aspects:

\section{A. Sharing of information resources}

With the development of computer technology, the basic characteristics of digital libraries are modern communication technology and network technology of information transmission, information sharing and virtualization of information entities. To accomplish full-text search and full download in the network environmentand information sharing, the database with characteristics should be built. In this way, the knowledge value of traditional literature re-embodies through network. 


\section{B. Offering distinguished service}

Distinguished Service is a new way of library service in recent years, which is based on the traditional one. The Construction of database with characteristicsembodies the distinguished information service of the university library and the transformation the services fromtraditional, passive and low-level to active knowledge value-added.It is a fundamental change in awareness and perceptions of the library service ${ }^{[2]}$. Databases with characteristicsprocessthe professional data, provide the readers with the retrieval technology of professional information, increase the accessing points, improve the searching efficiency and the rate of searching the whole text and precision, which makes the traditional readers' service much more deepened and comprehensive.

\section{Organizing and storing the information resources of each library}

The construction of databases with characteristicsmakes the separated literature resources a system,in order and deep-leveled, transforming the traditional literature resource to the digital one. These all lead to the convenience and safety of collection and storage of data.

\section{The content of database construction with characteristics}

In the content construction of databases with the characteristics of the key subjects, the great importance should be attached to the advantage of library's own resources.After the selection, classification and sorting of regular resources, it will lay the foundation for the databases with characteristics, with the complement of other special resources, in order to ensure the integrity ${ }^{[3]}$.

Generally includes: the database platform with characteristics, including academic repository(journals, theses, conference papers, etc.), briefing database, patent database, dynamic network information base,information navigation database, etc.. They give the resource availability and security to the scientific exchanges and research and development. Of course, for different subjects, the content, of course, is selected correspondingly.

\section{The principle of database construction with characteristics}

\section{A. The Principle of being distinguished}

Being distinguished is vital. The construction of database with the characteristics of particular subjects should embody some specialties and distinguished information resources, based on the schools' realities, so as to attract users and to avoid duplication and waste in construction The characteristics of subjects set the construction goal in particular topics, the interdisciplinary subjects or the frontier ones. The local characteristics of subjects have some geographical, historical and cultural features, or the resources closely related to the local politics, economy and cultural development. The characteristics of library collection is that they have the unique collection or the collection which the other university libraries rarely have, or the separated and unavailable resources

\section{B. The principle of high value}

The construction of database with the characteristic of subjects should take into consideration: the practical value, demand and the balance between input and output, that is, the result of social and economic benefits. The databases cannot be built without clear purpose, because the purpose of the construction of database with the characteristic of subjects is to realize the functions and the advantages of the university libraries in a better way, to bring remarkable benefits and their value.

\section{The principles of sustainability}

The construction of database with the characteristic of subjects shouldfollowdevelopment trend of the particular subjectsand the database itself, including the trends at home and abroad, such as, scale, type, multimedia, networking, etc ${ }^{[4]}$. This principle leaves us a better improving space, to find the destination suitable for our own, and to avoid some mistakes. 


\section{The principle of standardization}

The data can be shared only to settlestandardization issues. We could refer to the national standardized regulations of CALIS database construction, including metadata standard, data exchange standard, digital processing standard, etc., making the system ofdatabase with the characteristic of subjects in the unifiedframework of metadata set.

\section{E. The principle of richness}

According to the construction requirement of the core database of CALIS, the database should cover all types of documents related to the selected topics, including bibliography, abstract text, image, audio, video, etc. The actual content of database should have no less than three types of documents. The database should have a certain scale.

\section{F. The principle of sharing}

The university librarieswill always have some cross-cutting parts in resource construction of particular documents. Cooperation between libraries in the construction of database with the characteristic of subjects, andobeyingthe principles of the overall planning, joint development and jointly establishment make the information and technology exchanged and the resources shared; as for in the human resources, materials and finance,each aspect of which is fully used so are their advantages.In this way, it avoids constructing the repeated databases of the same subject and leaving blank subjects, so that the construction of each subject reaches a considerable degree of completeness. It paves the way for the resource sharing.

\section{Countermeasures of database construction}

\section{A. Improve the retrieval system of databases}

The university libraries should give full play to their own advantages, forming a distinguished database.The database companies also should think considerately for the users by standing in the shoes of the market and the users. Firstly, database developers should endeavor to unify the search platform, which provides an antecedent condition for the cross-database search.The developer also should work on repetition problems.Secondly, the database must be perfect in the search function. It should have a quick search function for the time of time saving, and also provide a variety of display and output, so that the users cansearch for the information in need. Finally, the database should be intelligent in retrieval language, so that the green-hands can easily make it.

\section{B. Selecting a suitable database construction software}

Selecting a suitable database construction software is a crucial step. Several aspects should be taken into consideration: firstly, the software support depends on the capacity and scale of the database. Since the nature and scale of the subjects differ one from another, the capacity and scale are different. For example, in the database, documents of Chinese articles are mainly text-based materials, but those of biological articles contain the samples, images, figures and tables, data, etc..Secondly, the familiarity in using the operation interface and the retrieval approaches also affect greatly. If the data type of the built database is similar to the frequently-used database in libraries of their own, it will not only make it easier for readers, but also increase the utilization rate of its own database.Thirdly,keeping the software in their own library the same with sharing software library,make it more convenient fordownloading and using of data exchange $\mathrm{e}^{[5]}$.

\section{Strengthening of database product marketing}

After years of development, the construction of databases with characteristics has made considerable progress on amount, scale and type. However, generally speaking, the rate of utilization is still relatively low. The database marketing is developing in low speed, digital services of distinguished resources focus largely on social benefits, not the economic benefit. The popularization and applicationof the database, rely on, on the one hand,the quality and advantages of the database itself, on the other hand,the database product promotion. Libraries should learn from the enterprises' marketing mode, combined with the market mechanism, so as to improve the 
application rate of database.

\section{Conclusion}

Before the construction of database with the characteristics of subjects, the universities should do some research on their subjects, that is, practice according to their realities. First of all, they should fully understand the subjects, their development history and interdisciplinary, etc., in order to determine the categories of the database. It is better to build a database with the characteristics of their school. Moreover, they should transform and process the information resources of distinguished documents of a particular subject, both in the library and on the Internet. Gradually, they will form a subject advantaged and systematic database system with the characteristics of subjects. Finally, the construction of database with the characteristics of subjects cannot be achieved in a day. Each university libraries should plan in a long-term run, demonstrating and designing from the overall perspective and applying in phases. In each phase of construction, they should set a clear goal and a proportion of capital investment, so as to build a database system with the characteristics of subjects of high level.The construction and implementation of database with the characteristics of subjects provide security sufficient information resources for the subject establishment.

\section{Acknowledgements}

This paper is the research finding of the 12th Five Year Plan of education science in Jilin Province "The construction and practice of support platform of universities' library rescourse and service facing to the construction of key disciplines" in the year of 2015 (Item Number: GH150212) and the research project of National Agricultural Literature Information Center of CALIS "The deep integration and further research of the library resources under the background of Big Data” in the year of 2015 (Item Number: 2015019)

\section{References}

[1] Jiang Dongying. Thoughts on the distinctive Database of the Academic Library, [J]. Journal of Library Science, 2011, (9):23-25.

[2] Cheng Jiejing. Investigation and Thinking of the current using situation of Thesis database Yunnan Universities Libraries, [J]. Information studies:Theory \& Application, 2011, (3): 86-90.

[3] Wang Xiaoli. On the Construction of distinctive Database of Local University Libraries, [J]. Library Work and Study, 2011, (11): 82-84.

[4] Zu Fanghong. On the Construction of distinctive Database of Anhui University Libraries, [J]. Information Science, 2010, (8): 1272-1277.

[5] Zhang Yanli. Discussions on the Construction of distinctive Database of University Libraries, [J]. Library Theory and Practice, 2011, (4): 92-93. 